\title{
Recent Advances in the Molecular Imaging of Programmed Cell Death: Part I-Pathophysiology and Radiotracers
}

\author{
Francis G. Blankenberg ${ }^{1}$ and H. William Strauss ${ }^{2}$ \\ ${ }^{I}$ Division of Pediatric Radiology, Department of Radiology, Lucile Salter Packard Children's Hospital, Stanford, California; and \\ ${ }^{2}$ Nuclear Medicine Service, Department of Radiology, Memorial Sloan-Kettering Cancer Center, New York, New York
}

\begin{abstract}
In humans, apoptosis (programmed cell death) is the most common form of cell death after necrosis. Apoptosis is a series of genetically preprogrammed biochemical and morphologic energy-requiring events that, after a specific external or internal stimulus, results in the physiologic disappearance of a cell via its self-disintegration and packaging of its contents into membrane vesicles called apoptotic bodies. Apoptotic bodies can readily be ingested, with their nutrients and even organelles recycled by neighboring cells or phagocytes without local inflammation. In contrast, necrosis is characterized by the primary loss of plasma membrane integrity and the uncontrolled release of a cell's contents, often causing local inflammation, tissue damage, and scarring. Alternate forms of cell death also exist, associated with specific molecular mechanisms involving enzymes, organelles, genes, external stimuli, or blockade of normal cell proliferation. In this review we will briefly outline the molecular mechanisms of apoptosis that can be imaged with radiotracers now under development.
\end{abstract}

Key Words: molecular imaging; oncology; apoptosis; programmed cell death

J Nucl Med 2012; 53:1659-1662

DOI: 10.2967/jnumed.112.108944

Apoptosis is the primary mechanism by which unneeded or senescent cells are physiologically absorbed by healthy adjacent cells and tissues (1). The term apoptosis (in Greek, a dropping or falling off of an organ or part) describes a complex series of morphologic events including cytoplasmic shrinkage, nuclear condensation, membrane blebbing, and budding off of intracellular contents, which are then packaged into small membrane-bound packets called apoptotic bodies. Apoptotic bodies are subsequently ingested by adjacent cells and phagocytes without provoking an inflammatory response or tissue damage. Apoptosis is the polar opposite of necrotic cell death, a chaotic event characterized by the uncontrolled primary failure of the cell membrane that frequently results in inflammation, tissue destruction, and scarring.

Received May 16, 2012; revision accepted Sep. 17, 2012.

For correspondence or reprints contact: Francis G. Blankenberg, Stanford/

Lucile Packard Children's Hospital, 725 Welch Rd., Palo Alto, CA 94304.

E-mail: blankenb@stanford.edu

Published online Oct. 2, 2012.

COPYRIGHT (C) 2012 by the Society of Nuclear Medicine and Molecular Imaging, Inc.
Although there is still no fully validated marker of apoptosis in vivo, there are several stereotypical pathophysiologic changes in the cell membrane, cytoplasm, and nucleus that can potentially be detected by a variety of new radiotracers (1). We will outline the most studied of these tracers after reviewing the pathophysiology of apoptosis.

\section{PATHOPHYSIOLOGY OF APOPTOSIS}

Apoptosis is a mechanism of orderly cell death $(2,3)$, as opposed to necrosis. Necrosis is characterized by the primary loss of outer membrane function and integrity, with uncontrolled swelling of a cell, its nucleus, and organelles coupled to the chaotic release of cellular contents into surrounding tissues. Other forms of cell death such as anoikis (cell death triggered by detachment of cells from the extracellular matrix), necroptosis (regulated necrosis requiring catalytic activity of a receptor interacting with protein kinase 1), mitotic catastrophe, and autoschizis have been described (4). Most of these other cell death mechanisms use some of the biochemical machinery required for apoptosis.

\section{Caspase-Dependent Apoptosis (Classic Pathways)}

The morphologic changes of apoptosis are preceded by an initiation phase triggered by a wide array of signals, including a lack of needed growth factors, antihormonal therapy, DNA damage, immune reactions, ischemic injury, ionizing radiation, and chemotherapy $(5,6)$. The lag time between exposure to the trigger and the time of observable morphologic signs of apoptosis is highly variable, depending heavily on cell type, type of trigger, its intensity and duration, and the local environmental conditions of the cell.

Most apoptotic pathways, however, converge on a family of cysteine aspartate-specific proteases known as the caspases (Fig. 1) (7). The terminal effector caspase, caspase-3, once activated by death receptors on the cell surface (extrinsic pathway) or via the release of cytochrome $\mathrm{c}$ from the mitochondria (intrinsic pathway), travels to the nucleus and facilitates the cleavage of nuclear DNA. Caspase-3 also cleaves poly-ADP-ribose polymerase (PARP-1), a DNA repair enzyme-an event that prevents any chance of cell survival.

After caspase-3 activation, there is a rapid redistribution and exposure of the anionic membrane-bound phospholipid phosphatidylserine (PS) on the cell surface (Fig. 1) $(8,9)$. PS 


\section{FIGURE 1. Molecularly targeted radiotracers.}

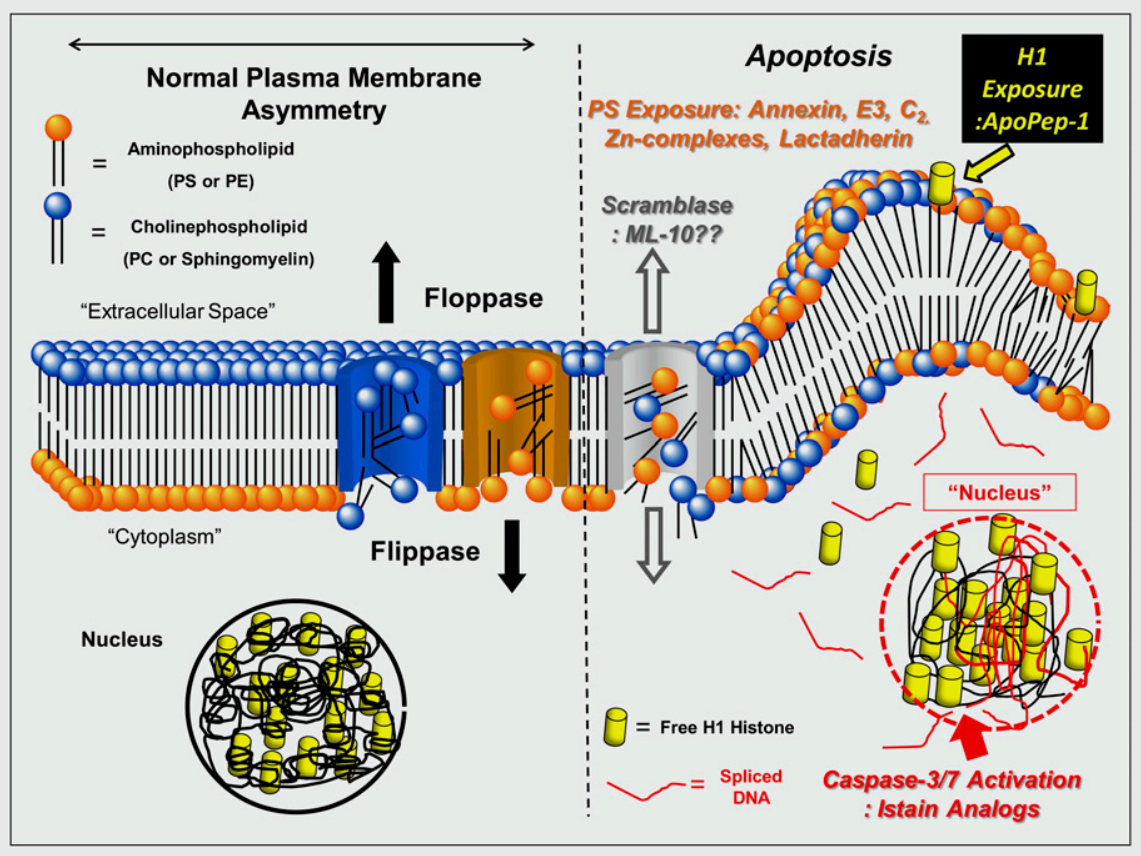

is normally restricted to the inner leaflet of the lipid bilayer by an adenosine triphosphate-dependent enzyme called flippase (translocase). Flippase in concert with a second adenosine triphosphate-dependent enzyme, floppase, that pumps cationic phospholipids such as phosphatidylcholine (PC) and sphingomyelin to the cell surface, maintains an asymmetric distribution of different phospholipids between the inner and outer leaflets of the plasma membrane (10). The rapid redistribution across the cell membrane (measured in minutes) is facilitated by a calcium-dependent deactivation of flippase and the activation of a third enzyme called scramblase.

\section{Other Signaling Pathways That Can Induce Cell Death}

The endoplasmic reticulum (ER) can also trigger apoptosis (i.e., ER stress-induced cell death) (11). Normally, the ER is the site of protein synthesis, conformational maturation, and quality control for correctly folded proteins. Proteins failing to adopt a stable conformation are dislocated into the cytosol, where they are targeted for ubiquitylation (a tag to identify a protein for elimination) and proteosomal degradation. Certain conditions or drugs can lead to the abnormal accumulation of unfolded proteins resulting in ER stress. During ER stress, cells can reachieve homeostasis by initiating a series of orchestrated events known as the unfolded protein response. If unsuccessful, ER stress can directly initiate a specific ubiquitin $\mathrm{E}_{3}$ ligase that tags antiapoptotic proteins (e.g., Bcl-2) with ubiquitin. Subsequently, the proteosome degrades these antiapoptotic molecules, thereby tipping the balance between pro- and antiapoptotic factors toward the intrinsic pathway of apoptosis.

Other forms of cell death can also externalize PS, including necrosis/oncosis, mitotic catastrophe, cell senescence, pyroptosis, PARP-1-mediated cell death, and autophagy (12). Autophagy ("self-eating") has considerable overlap with apop- tosis (13). As opposed to apoptosis, however, autophagy normally serves a housekeeping function by recycling senescent or damaged cytoplasmic contents or organelles (as opposed to the cell itself). The hallmark of autophagy is the formation of isolation membranes that engulf targeted cytoplasmic material (or organelles), resulting in double-membraned vesicles called autophagosomes (autophagic vacuoles) (14). Autophagosomes then undergo maturation by fusion with lysosomes to create autolysosomes. It is within the autolysosome that autodigestion occurs. Autophagy permits a cell to survive periods of cellular famine through the autodigestion and reuse of intracellular DNA/RNA, proteins, and lipids into free nucleotides, amino acids, and fatty acids, respectively. Autophagy, however, can be an alternative to apoptosis if the classic apoptotic mechanisms are damaged or are inhibited.

\section{RADIOTRACERS FOR APOPTOSIS}

\section{PARP-1-Mediated Cell Death/Oncosis}

PARP-1 normally functions as a DNA damage sensor, and its activation serves to repair low levels of DNA damage (15). With high levels of DNA damage, however, there is massive activation of PARP-1 that consumes all available stores of nicotinamide adenine dinucleotide (in the oxidized state) $\left(\mathrm{NAD}^{+}\right)$, its primary substrate. As $\mathrm{NAD}^{+}$can be regenerated only by cleavage of adenosine triphosphate, the cell literally runs out of energy and dies via necrosis. Olaparib, an experimental chemotherapeutic benzimidazole-based inhibitor (and its indole analogs) of PARP-1, can also be derivatized and labeled with ${ }^{18} \mathrm{~F}$ for PET of PARP-1-mediated cell death (16). These agents are now under development and are superior to the previous ${ }^{11} \mathrm{C}$-labeled phenanthridone PARP-1 binding derivative known as PJ34 (17). 


\section{The PS Binding Agent Radiolabeled Annexin V}

PS selectively exposed on the cell surface during apoptosis can be imaged with a variety of agents. One such radiotracer uses annexin $\mathrm{V}$, an intracellular human protein (molecular weight, $\sim 36,000$ ) with a nanomolar affinity for membrane-bound PS (18-20). Although the bifunctional ${ }^{99 \mathrm{~m}} \mathrm{Tc}$ chelating agent hydrazinonicotinamide has been used for most animal and clinical radiolabeled annexin $\mathrm{V}$ studies to date, there are alternative methods including self-chelating annexin $\mathrm{V}$ mutants with a cysteine-containing N-terminal 6 amino acid tag that can bind ${ }^{99 \mathrm{~m}} \mathrm{Tc}$ (21-23). These mutants have major advantages over hydrazinonicotinamide-annexin V, including a $50 \%-75 \%$ decreased renal uptake of tracer and a markedly improved (2- to 3-fold) specific localization to sites of apoptosis in animal models $(24,25)$. Annexin $\mathrm{V}$ has also been labeled with ${ }^{18} \mathrm{~F}$ (26). using $N$-succinimidyl 4 -fluorobenzoate or site-specific derivatization with ${ }^{18} \mathrm{~F}$-maleimide-labeled mutant annexin V-128 (27).

\section{Other PS Binding Agents}

Other peptides and proteins have been found that can recognize membrane-bound PS (28). These include the C2A domain of synaptotagmin I. C2A binds to negatively charged phospholipids in membranes, including PS. C2A and its mutants have been labeled with ${ }^{99 \mathrm{~m}} \mathrm{Tc}$ (29) iron particles $(24,30)$ and $\mathrm{Gd} 3+(25)$. C2A complexes have yet to be tested on humans (31).

Other approaches to detect the membrane changes of apoptosis include the small-molecule zinc-dipicolylamine coordination complex (32) and cationic liposomes (33). CLSYYPSYC, a PS-binding peptide, has been described; however, its mechanism of PS binding has yet to be elucidated (34-36). The same group of investigators also identified ApoPep-1, a 6-amino-acid CQRPPR peptide that recognizes histone ${ }^{1} \mathrm{H}$ exposed on the surface of apoptotic cells (37). Preliminary imaging experiments with ${ }^{124} \mathrm{I}-\mathrm{ApoPep}-1$ in treated murine tumors are also encouraging.

\section{Imaging of Caspase-3 Activity}

The backbone of caspase-seeking tracers is based on the 5-pyrrolidinylsulfonyl isatin class of nonpeptidyl caspase inhibitors $(38,39)$. The dicarbonyl function of isatins covalently binds to the cysteine residue of the active site of a given caspase. There is a need, however, to generate isatin sulfonamides that have higher metabolic stability and more moderate lipophilicity while retaining selectivity and affinity for caspase-3 and -7, including a 2 '-fluoroethyl-1,2,3triazole with subnanomolar affinity for caspase- 3 that has been identified $(40,41)$. Other isatin analogs may have improved localization to sites of apoptosis in vivo $(42,43)$.

\section{${ }^{18}$ F-FDG PET of Apoptosis}

Tumor models have demonstrated an enhanced apoptotic reaction that correlated with suppressed tumor glucose utilization $48 \mathrm{~h}$ after the start of cytotoxic chemotherapy (44-46), as have patients with gastrointestinal stromal tumor treated with the tyrosine kinase inhibitor imatinib mesylate (STI571; Gleevec) (47) and epidermal growth factor receptor kinase inhibition of non-small cell lung cancer with gefitinib (28). However, because apoptosis must use energy, at least initially, glucose demand may increase temporarily in some unique clinical situations $(48,49)$.

\section{Uncategorized Radiotracers for the Imaging of Apoptosis}

Aposense molecules are another family of radiotracers (50-52). These small molecules have an amphipathic structure, with both specific hydrophobic and charged moieties. The published doses are 100- to 1,000-fold higher on a molar basis for these agents than for other classes of agents with very low specific uptakes. The most recent of these tracers, known as ML-10, has been applied to the study of apoptotic tumor cells in vitro and in vivo (53). Despite an improvement in uptake, the absolute uptake values remain low $(<1.5 \%$ injected dose/g) even for tumors treated with high-dose chemotherapy (i.e., at the 50\% lethal dose) (5457) - doses high enough to induce necrosis and raising the question of the mechanism of tracer localization.

\section{SUMMARY}

Although remarkable progress has been made in the development of PET and SPECT radiotracers and apoptosis-specific radiotracers, much work still needs to be done to bring any of these agents into routine use in the clinic. Most preclinical and clinical trial work has been done with different forms of radiolabeled annexin V. In the short term, the Canadian company Atreus Pharmaceuticals, Inc., in conjunction with its European partner, Advanced Accelerator Applications, SA, is developing a kit for the preparation of ${ }^{99 \mathrm{~m}} \mathrm{Tc}$ rh-annexin $\mathrm{V}-128$, which is expected to be in human studies shortly and is expected to be made available for investigator-sponsored preclinical and clinical studies. Long-term caspase- or PARP-1-binding or ${ }^{1} \mathrm{H}$-recognizing radiotracers may be useful complements to the imaging of PS expression.

\section{ACKNOWLEDGMENT}

No potential conflict of interest relevant to this article was reported.

\section{REFERENCES}

1. Blankenberg FG, Norfray JF. Multimodality molecular imaging of apoptosis in oncology. AJR. 2011;197:308-317.

2. Ameisen JC. On the origin, evolution, and nature of programmed cell death: a timeline of four billion years. Cell Death Differ. 2002;9:367-393.

3. Fink SL, Cookson BT. Apoptosis, pyroptosis, and necrosis: mechanistic description of dead and dying eukaryotic cells. Infect Immun. 2005;73:1907-1916.

4. Galluzzi L, Vitale I, Abrams JM, et al. Molecular definitions of cell death subroutines: recommendations of the Nomenclature Committee on Cell Death. Cell Death Differ. 2012;19:107-120.

5. Chan A, Reiter R, Wiese S, Fertig G, Gold R. Plasma membrane phospholipid asymmetry precedes DNA fragmentation in different apoptotic cell models. Histochem Cell Biol. 1998;110:553-558. 
6. Martin SJ, Reutelingsperger CPM, McGahon AJ. Early redistribution of plasma membrane phosphatidylserine is a general feature of apoptosis regardless of the initiating stimulus: inhibition by overexpression of Bcl-2 and Abl. J Exp Med. 1995;182:1545-1556.

7. Huerta S, Goulet EJ, Huerta-Yepez S, Livingston EH. Screening and detection of apoptosis. J Surg Res. 2007;139:143-156.

8. Zwaal RFA, Schroit AJ. Pathophysiologic implications of membrane phospholipid asymmetry in blood cells. Blood. 1997;89:1121-1132.

9. Zwaal RFA, Comfurius P, Bevers EM. Surface exposure of phosphatidylserine in pathological cells. Cell Mol Life Sci. 2005;62:971-988.

10. Wood BL, Gibson DF, Tait JF. Increased phosphatidylserine exposure in sickle cell disease: flow cytometric measurement and clinical associations. Blood. 1996;88:1873-1880.

11. Egger L, Madden DT, Rheme C, Rao RV, Bredesen DE. Endoplasmic reticulum stress-induced cell death mediated by the proteasome. Cell Death Differ. 2007; 14:1172-1180.

12. Verheij M. Clinical biomarkers and imaging for radiotherapy-induced cell death. Cancer Metastasis Rev. 2008;27:471-480.

13. Levine B, Kroemer G. Autophagy in the pathogenesis of disease. Cell. 2008;132: 27-42.

14. Maiuri MC, Zalckvar E, Kimchi A, Kroemer G. Self-eating and self-killing: crosstalk between autophagy and apoptosis. Nat Rev Mol Cell Biol. 2007;8: 741-752.

15. Aguilar-Quesada R, et al. Modulation of transcription by PARP-1: consequences in carcinogenesis and inflammation. Curr Med Chem. 2007;14:1179-1187.

16. Keliher EJ, Reiner T, Turetsky A, Hilderbrand SA, Weissleder R. High-yielding, two-step ${ }^{18} \mathrm{~F}$ labeling strategy for ${ }^{18} \mathrm{~F}$-PARP1 inhibitors. ChemMedChem. 2011; 6:424-427.

17. Tu Z, Chu W, Zhang J, Dence CS, Welch MJ, Mach RH. Synthesis and in vivo evaluation of $\left[{ }^{11} \mathrm{C}\right] \mathrm{PJ} 34$, a potential radiotracer for imaging the role of PARP-1 in necrosis. Nucl Med Biol. 2005;32:437-443.

18. Boersma HH, Kietselaer BL, Stolk LM, et al. Past, present, and future of annexin A5: from protein discovery to clinical applications. J Nucl Med. 2005;46:2035-2050.

19. Lahorte CMM, Vanderheyden J-L, Steinmetz N, Van de Wiele C, Dierckx RA, Slegers G. Apoptosis-detecting radioligands: current state of the art and future perspectives. Eur J Nucl Med Mol Imaging. 2004;31:887-919.

20. Munoz LE, Frey B, Pausch F, et al. The role of annexin A5 in the modulation of the immune response against dying and dead cells. Curr Med Chem. 2007:14: 271-277.

21. Tait JF, Brown DS, Gibson DF, Blankenberg FG, Strauss HW. Development and characterization of annexin $\mathrm{V}$ mutants with endogenous chelation sites for ${ }^{99 \mathrm{~m}} \mathrm{Tc}$. Bioconjug Chem. 2000;11:918-925.

22. Jin M, Smith C, Hsieh HY, Gibson DF, Tait JF. Essential role of B-helix calcium binding sites in annexin V-membrane binding. J Biol Chem. 2004;279:40351-40357.

23. Tait JF, Smith C, Blankenberg FG. Structural requirements for in vivo detection of cell death with ${ }^{99 \mathrm{~m}} \mathrm{Tc}$-annexin V. J Nucl Med. 2005;46:807-815.

24. Zhao M, Beauregard DA, Loizou L, Davletov B, Brindle KM. Non-invasive detection of apoptosis using magnetic resonance imaging and a targeted contrast agent. Nat Med. 2001;7:1241-1244.

25. Krishnan AS, Neves AA, de Backer MM, et al. Detection of cell death in tumors by using MR imaging and a gadolinium-based targeted contrast agent. Radiology. 2008;246:854-862.

26. Murakami Y, Takamatsu H, Taki J, et al. ${ }^{18} \mathrm{~F}$-labelled annexin V: a PET tracer for apoptosis imaging. Eur J Nucl Med Mol Imaging. 2004;31:469-474.

27. Li X, Link JM, Stekhova S, et al. Site-specific labeling of annexin V with F-18 for apoptosis imaging. Bioconjug Chem. 2008;19:1684-1688.

28. Su H, Bodenstein C, Dumont RA, et al. Monitoring tumor glucose utilization by positron emission tomography for the prediction of treatment response to epidermal growth factor receptor kinase inhibitors. Clin Cancer Res. 2006;12: 5659-5667.

29. Zhao M, Zhu X, Ji S, et al. ${ }^{99 m}$ Tc-labeled C2A domain of synaptotagmin I as a target specific molecular probe for noninvasive imaging of acute myocardial infarction. J Nucl Med. 2006;47:1367-1374.

30. Jung HI, Kettunen MI, Davletov B, Brindle KM. Detection of apoptosis using the C2A domain of synaptotagmin I. Bioconjug Chem. 2004;15:983-987.

31. Alam IS, Neves AA, Witney TH, Boren J, Brindle KM. Comparison of the C2A domain of synaptotagmin-I and annexin- $\mathrm{V}$ as probes for detecting cell death. Bioconjug Chem. 2010;21:884-891.

32. Hanshaw RG, Lakshmi C, Lambert TN, Johnson JR, Smith BD. Fluorescent detection of apoptotic cells by using zinc coordination complexes with a selective affinity for membrane surfaces enriched with phosphatidylserine. ChemBioChem. 2005;6:2214-2220
33. Bose S, Tuunainen I, Parry M, Medina OP, Mancini G, Kinnunen PK. Binding of cationic liposomes to apoptotic cells. Anal Biochem. 2004;331:385-394.

34. Shao R, Xiong C, Wen X, Gelovani JG, Li C. Targeting phosphatidylserine on apoptotic cells with phages and peptides selected from a bacteriophage display library. Mol Imaging. 2007;6:417-426.

35. Thapa $\mathrm{N}$, et al. Discovery of a phosphatidylserine-recognizing peptide and its utility in molecular imaging of tumour apoptosis. J Cell Mol Med. 2008;12: 1649-1660.

36. Schellenberger EA, Sosnovik D, Weissleder R, Josephson L. Magneto/optical annexin V, a multimodal protein. Bioconjug Chem. 2004;15:1062-1067.

37. Wang $\mathrm{K}$, et al. In vivo imaging of tumor apoptosis using histone H1-targeting peptide. J Control Release. 2010;148:283-291.

38. Zhou D, Chu W, Rothfuss J, et al. Synthesis, radiolabeling, and in vivo evaluation of an ${ }^{18} \mathrm{~F}$-labeled isatin analog for imaging caspase- 3 activation in apoptosis. Bioorg Med Chem Lett. 2006;16:5041-5046.

39. Faust A, Wagner S, Law MP, et al. The nonpeptidyl caspase binding radioligand (S)-1-(4-(2-[ ${ }^{18}$ F]fluoroethoxy)-benzyl)-5-[1-(2-methoxymethylpyrrolidinyl)sulfonyl] isatin $\left(\left[{ }^{18} \mathrm{~F}\right] \mathrm{CbR}\right)$ as potential positron emission tomography-compatible apoptosis imaging agent. Q J Nucl Med Mol Imaging. 2007;51:67-73.

40. Smith G, Glaser M, Perumal M, et al. Design, synthesis, and biological characterization of a caspase $3 / 7$ selective isatin labeled with $2-\left[{ }^{18} \mathrm{~F}\right]$ fluoroethylazide. J Med Chem. 2008;51:8057-8067.

41. Nguyen Q-D, Smith G, Glaser M, Perumal M, Årstadb E, Aboagye EO. Positron emission tomography imaging of drug-induced tumor apoptosis with a caspase3/7 specific $\left[{ }^{18} \mathrm{~F}\right]$-labeled isatin sulfonamide. Proc Natl Acad Sci U S A. 2009; 106:16375-16380

42. Chen DL, et al. Comparison of radiolabeled isatin analogs for imaging apoptosis with positron emission tomography. Nucl Med Biol. 2009;36:651-658.

43. Zhou D, Zhou D, Chu W, et al. $\left[{ }^{18} \mathrm{~F}\right]-$ and $\left[{ }^{11} \mathrm{C}\right]$-labeled N-benzyl-isatin sulfonamide analogues as PET tracers for apoptosis: synthesis, radiolabeling mechanism, and in vivo imaging study of apoptosis in Fas-treated mice using $\left[{ }^{11} \mathrm{C}\right]$ WC-98. Org Biomol Chem. 2009; 7:1337-1348.

44. Takei T, Kuge Y, Zhao S, et al. Enhanced apoptotic reaction correlates with suppressed tumor glucose utilization after cytotoxic chemotherapy: use of ${ }^{99 \mathrm{~m}} \mathrm{Tc}-$ annexin V, ${ }^{18} \mathrm{~F}-\mathrm{FDG}$, and histologic evaluation. J Nucl Med. 2005;46:794-799.

45. Li D, Yao Q, Li L, Wang L, Chen J. Correlation between hybrid ${ }^{18} \mathrm{~F}-\mathrm{FDG}$ PET/CT and apoptosis induced by neoadjuvant chemotherapy in breast cancer. Cancer Biol Ther. 2007;6:1442-1448.

46. Suttie SA, Park KGM, Smith TAD. $\left[{ }^{18} \mathrm{~F}\right]$-2-fluoro-2-deoxy-D-glucose incorporation by AGS gastric adenocarcinoma cells in vitro during response to epirubicin, cisplatin and 5-fluorouracil. Br J Cancer. 2007;97:902-909.

47. Trent JC, et al. Early effects of imatinib mesylate on the expression of insulin-like growth factor binding protein-3 and positron emission tomography in patients with gastrointestinal stromal tumor. Cancer. 2006;107:1898-1908.

48. Haberkorn U, Bellemann ME, Brix G, et al. Apoptosis and changes in glucose transport early after treatment of Morris hepatoma with gemcitabine. Eur J Nucl Med. 2001;28:418-425.

49. Mortimer JE, Dehdashti F, Siegel BA, et al. Metabolic flare: indicator of hormone responsiveness in advanced breast cancer. J Clin Oncol. 2001;19: 2797-2803.

50. Reshef A, Shirvan A, Grimberg H, et al. Novel molecular imaging of cell death in experimental cerebral stroke. Brain Res. 2007;1144:156-164.

51. Damianovich M, Ziv I, Heyman SN, et al. ApoSense: a novel technology for functional molecular imaging of cell death in models of acute renal tubular necrosis. Eur J Nucl Med Mol Imaging. 2006;33:281-291.

52. Aloya R, Shirvan A, Grimberg H, et al. Molecular imaging of cell death in vivo by a novel small molecule probe. Apoptosis. 2006;11:2089-2101.

53. Grimberg H, Levin G, Shirvan A, et al. Monitoring of tumor response to chemotherapy in vivo by a novel small-molecule detector of apoptosis. Apoptosis. 2009; 14:257-267.

54. Cheng C, Xue W, Diao H, et al. Antitumor activity and toxicological properties of doxorubicin conjugated to $\alpha, \beta$-poly[(2-hydroxyethyl)-L-aspartamide] administered intraperitoneally in mice. Anticancer Drugs. 2010;21:362-371.

55. Meer L, Schold SC, Kleihues P. Inhibition of the hepatic O6-alkylguanine-DNA alkyltransferase in vivo by pretreatment with antineoplastic agents. Biochem Pharmacol. 1989;38:929-934.

56. Steen RG, Tamargo RJ, Brem H, Glickson JD, Wehrle JP. In vivo ${ }^{31} \mathrm{P}$ nuclear magnetic resonance spectroscopy of rat $9 \mathrm{~L}$ gliosarcoma treated with $\mathrm{BCNU}$ : dose response of spectral changes. Magn Reson Med. 1989;11:258-266.

57. Weinberg MJ, Rauth AM. 5-Fluorouracil infusions and fractionated doses of radiation: studies with a murine squamous cell carcinoma. Int J Radiat Oncol Biol Phys. 1987;13:1691-1699. 